\title{
Speed or sperm: A potential trade-off between development and reproduction in the butterfly, Bicyclus anynana (Lepidoptera: Nymphalidae)
}

\author{
ZENOBIA LEWIS ${ }^{1}$, PAUL M. BRAKEFIELD ${ }^{2}$ and NINA WEDELL ${ }^{3}$ \\ ${ }^{1}$ Graduate School of Environmental Science, Okayama University, Okayama 700-0084, Japan; e-mail: zen.lewis@gmail.com \\ ${ }^{2}$ Institute of Biology, Leiden University, PO Box 9505, 2300 RA Leiden, The Netherlands; \\ e-mail: p.m.brakefield@biology.leidenuniv.nl \\ ${ }^{3}$ Centre for Ecology and Conservation, University of Exeter, Cornwall Campus, Tremough, Penryn, Cornwall, TR10 9EZ, UK; \\ e-mail: n.wedell@exeter.ac.uk
}

Key words. Lepidoptera, Nymphalidae, Bicyclus anynana, reproduction, trade-off, development time, polymorphic sperm

\begin{abstract}
Life-history theory predicts trade-offs between resources invested in reproduction and other fitness-related traits. To date, most studies have focused on potential reproductive trade-offs in females. However, it is now generally accepted that reproduction is also costly for males, and thus males too may be subject to trade-offs. We examined the relationship between development time and the production of both fertile and non-fertile sperm in males of the African bush brown butterfly (Bicyclus anynana) selected for short or long pre-adult development time. Fast developing males ejaculated fewer non-fertile sperm on their first mating, suggesting that there could be a trade-off between ejaculate production and development time in this species. Contrary to predictions, slow developing males were smaller, produced fewer fertile sperm and took longer to mate. We discuss why this might be the case, and suggest that there may be a cost to the production of non-fertile sperm in the Lepidoptera.
\end{abstract}

\section{INTRODUCTION}

The evolution of an organism is shaped by trade-offs between traits related to fitness (Roff, 2002). Individuals possess finite resources from which both somatic and reproductive demands must be satisfied. Therefore, higher investment in one will decrease the resources available for investment in the other. There is a wealth of studies reporting trade-offs in females between reproduction and other life-history traits such as longevity (e.g. Chapman et al., 1998; Jervis et al., 2005), but fewer studies have examined such trade-offs in males. This may, in part, be because traditional consensus holds that males possess an almost unlimited supply of cheap sperm (Bateman, 1948). However, although males usually have greater reproductive potential than females, it is now recognised that in many species, males are limited in sperm and ejaculate production (reviewed in Wedell et al., 2002).

In the Lepidoptera, males transfer sperm to the female within a sperm packet or spermatophore. The spermatophore can represent a substantial investment for males; successive spermatophores are often of lower mass (e.g. Cook \& Wedell, 1996) and may contain fewer sperm (e.g. Lewis \& Wedell, 2007). In addition, in many species, males require a period of recovery following copulation (e.g. Bissoondath \& Wiklund, 1996), and successive copulations often increase in duration (e.g. Kaitala \& Wiklund, 1995). This high investment in reproduction can result in trade-offs against somatic maintenance; for example in the Indian meal moth, Plodia interpunctella, nutritional stress during development constrains sperm production, suggesting a cost of producing sperm in this species (Gage \& Cook, 1994).

Male butterflies and moths are sperm polymorphic, producing both fertile "eupyrene" sperm, and anucleated, non-fertile "apyrene" sperm (Meves, 1902). Both types are transferred to the female during copulation, and nonfertile sperm can constitute up to $95 \%$ of an ejaculate (Cook \& Wedell, 1996). Since their discovery over a century ago, many hypotheses have been proposed for the function of non-fertile sperm (reviewed by Silberglied et al., 1984) but recent evidence suggests that in at least one butterfly species, they have a role in sperm competition (Cook \& Wedell, 1999), by filling the female sperm storage organ and delaying female receptivity. Following mating, female Lepidoptera are generally subject to a refractory period, during which they either stop releasing male attractant pheromones (in moths), or reject the advances of courting males (in butterflies) (Drummond, 1984). This behaviour is thought to be induced either through physical stimulation provided by the spermatophore, or by the presence of sperm and/or seminal fluid components within the female sperm storage organ (reviewed in Wedell, 2005). It has been suggested that filling the sperm storage organ with non-fertile sperm in order to delay female remating, may be cheaper or more efficient for males than ejaculating larger numbers of fertile sperm (Silberglied et al., 1984).

Development time is an important life history trait, and is closely related to fitness in many species (reviewed in Roff, 1992). Fast development is often associated with increased fitness due to, for example, decreased probability of larval mortality (e.g. Benrey \& Denno, 1997). 
However, one might expect that investment in fast development may result in a trade-off against investment in other life-history traits. In some Lepidopteran species for example, a high larval growth rate can be costly in terms of reduced starvation resistance (Gotthard et al., 1994) or increased predation risk (Gotthard, 2000). The African bush brown butterfly, Bicyclus anynana (Butler, 1879), is protandrous: generally males eclose before females (Zijlstra et al., 2002; Zwaan et al., 2008). In this species fast developing males are therefore at an advantage as they are more likely to encounter virgin females. In the wild approximately one third of $B$. anynana females remate (Brakefield \& Reitsma, 1991), and in the laboratory one quarter of females remate (Brakefield et al., 2001). Thus by emerging earlier, and thereby increasing the likelihood of encountering virgin females, males can avoid sperm competition and maximise their reproductive success (Wiklund \& Fagerström, 1977). However, it has been suggested that sperm and spermatophore production are costly for males of this species; the numbers of both fertile and non-fertile sperm decrease with consecutive matings, and male adult longevity is negatively correlated with non-fertile sperm production (Lewis \& Wedell, 2007). Potentially, increased investment in fast development may deplete the resources available for sperm production. Here we use artificial selection to examine whether there is a trade-off between these two fitnessrelated traits in male $B$. anynana.

\section{MATERIAL AND METHODS}

Lines selected for fast and slow development were produced from a long established laboratory population of Bicyclus anynana originating from 80 gravid females collected at Nkhata Bay, Malawi, in 1988 (Zijlstra et al., 2001). A detailed description of the selection protocol is given by Pijpe et al. (2006). Briefly, larvae were reared on maize plants (Zea mays) and adults were provided with moist banana ad lib. Eggs were collected from the stock population over a $12 \mathrm{~h}$ period, and reared together. Approximately the first 50 males and 50 females to eclose were placed in a mating cage and allowed to mate freely. Similarly, the last 50 males and 50 females to eclose were placed in a mating cage and allowed to mate freely. Eggs were collected from the two founding populations over a $12 \mathrm{~h}$ period, and the larvae reared together forming the "fast developing" line and the "slow developing" line, respectively. This has been repeated, with individuals mated and reared within the two lines, for many generations. Throughout the experiment, adults and larvae were kept in a controlled temperature room at $27^{\circ} \mathrm{C}$ with a $12 \mathrm{~L}: 12 \mathrm{D}$ cycle. Due to practical limitations, only one replicate of each selection treatment was established. However, the results of previous studies utilising these lines (c.f. Pijpe et al., 2006) suggest that the observed phenotypic divergence has a clear genetic basis, rather than being the result of random drift.

After approximately 120 generations of selection for the "fast" developing phenotype, and 60 generations for the "slow" phenotype, the lines had diverged for development time with males from "slow" taking on average 41 ( \pm 4.58 s.d.) days to develop from egg to adult, and males from the "fast" lines taking only 34 ( \pm 4.04 s.d.) days to reach adulthood. At this stage, male ejaculate production was measured. Ejaculate production was also measured in unselected, stock males from the original population. This population has been maintained under similar conditions to the selected lines.
Male pupae were removed from the rearing cages. Following eclosion, the virgin adults were uniquely numbered on the wing. Matings took place the day after eclosion. At 10 am males were released into a mating cage with equal numbers of virgin, unselected, stock females that were between one and four days old. Females had been numbered uniquely following eclosion as the males. Copulation in B. anynana lasts for approximately $30 \mathrm{~min}$ (Joron \& Brakefield, 2003), therefore cages were inspected every fifteen minutes for mating pairs, whom, on discovery, were captured and isolated in plastic cups. Upon separation, the male's identification number and age was noted, and he was then removed from the experiment. The female was immediately transferred to $\mathrm{a}-20^{\circ} \mathrm{C}$ freezer to prevent sperm migration from the spermatophore. Mating was allowed to continue for four hours until $2 \mathrm{pm}$. At this point, all females were removed to a separate holding cage. The above procedure was continued each day until all males had mated once.

Following the end of the experiment, the wings of all males and females were removed, and body sizes estimated by measuring the length of a cross vein, close to the wing's intersection with the body. In addition, the abdomens of all females were dissected and the numbers of both fertile and non-fertile sperm counted using standard protocol (Lewis \& Wedell, 2007). The intact spermatophore was removed from each female and placed in a drop of modified Barth Saline solution (Gurdon, 1991) in a cavity slide. Using a dissecting microscope at $\times 16$ magnification, the spermatophore was pulled apart using fine forceps to release the sperm and the sperm mass gently stirred. During copulation, fertile sperm are transferred to the female in bundles, each of which contains 256 sperm (Cook \& Wedell, 1996). These bundles, which are clearly visible under a dissecting microscope, were counted and then multiplied by 256 to give the total number of sperm present in each spermatophore.

Non-fertile sperm are much smaller than fertile sperm and are not visible at $\times 16$ magnification. In order to count the number of non-fertile sperm in each spermatophore, the contents of the cavity slide were washed into a $30 \mathrm{ml}$ universal tube and diluted with a known volume of distilled water. The sample was agitated gently to disperse the sperm, and six $10 \mu \mathrm{l}$ sub-samples were removed and transferred to a microscope slide using a Gilson pipette. The dried samples were examined using a dark field phase contrast microscope at $\times 100$ magnification. All nonfertile sperm in each of the sub-samples were counted and an average obtained. The total number of non-fertile sperm in each spermatophore was then estimated by multiplying the mean 10 $\mu 1$ sperm count by its dilution factor.

All analyses were performed in $\mathrm{R}$ (version 2.0.1). The impact of male selection history on transfer of fertile and non-fertile sperm on the males' first mating was analysed using Generalized Linear Models with male and female size as covariates and specifying a Poisson error distribution (data corrected for overdispersion) (Crawley, 2005). We conducted a stepwise removal of factors to produce the final minimal model.

\section{RESULTS}

Although the lack of selection line replication in our study means that our results should be interpreted with caution, there was evidence that selection treatment affected males' sperm transfer. Fast developing males transferred fewer non-fertile sperm compared to both slow and unselected stock males $(\mathrm{F}=5.49, \mathrm{p}=0.008, \mathrm{df}$ $=42$, Fig. 1) and this was also related to the number of fertile sperm transferred $(F=9.60, p=0.0036$, df $=40)$. In contrast, slow developing males transferred significantly fewer fertile sperm than fast developing and stock 


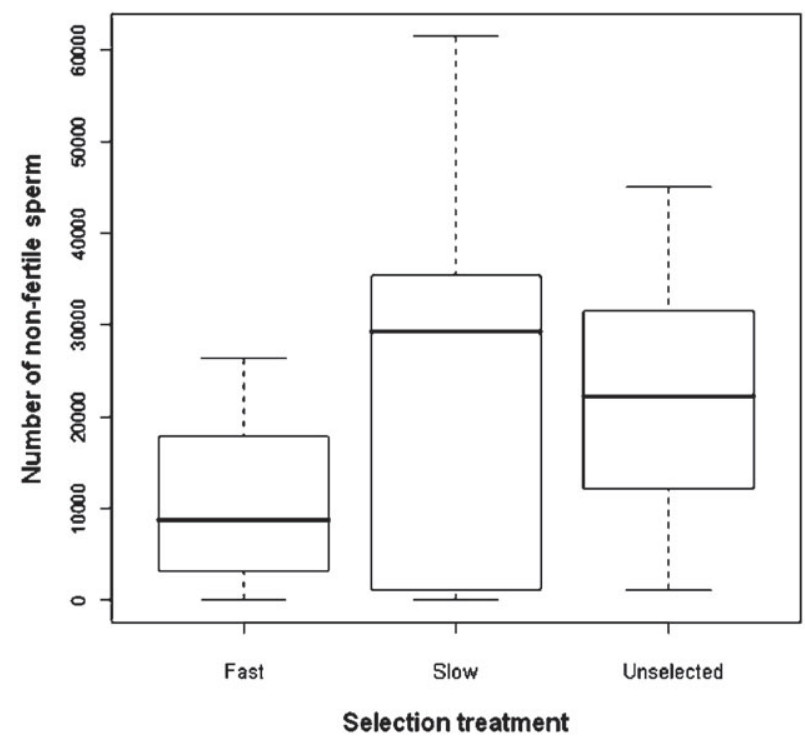

Fig. 1. Male B. anynana selected for fast development time produce fewer non-fertile sperm on their first mating than unselected stock males, and males selected for slow development (values are medians \pm upper and lower quartiles).

males $(\mathrm{F}=4.22, \mathrm{p}=0.0223$, $\mathrm{df}=37$, Fig. 2$)$, and this was influenced by both male age $(\mathrm{F}=3.05, \mathrm{p}=0.0316$, df $=$ $37)$ and the number of non-fertile sperm transferred $(\mathrm{F}=$ $4.83, \mathrm{p}=0.0196, \mathrm{df}=37)$. There was no effect of male or female body size on the number of fertile or non-fertile sperm transferred $(\mathrm{p}>0.4)$.

Males from the slow developing selection line were smaller than males from the fast developing lines or unselected stock lines $(\mathrm{F}=7.97, \mathrm{p}=0.0013$, $\mathrm{df}=40$, Fig. 3 ). Slow developing males also took longer before mating ( $\mathrm{F}$ $=5.25, \mathrm{p}=0.0088, \mathrm{df}=46$; fast males: median 2 days, range 2-4; stock males: median 2 days, range $0-5$; slow



Fig. 2. Male B. anynana selected for slow development time produce fewer fertile sperm on their first mating than unselected stock males, and males selected for fast development time (values are medians \pm upper and lower quartiles).

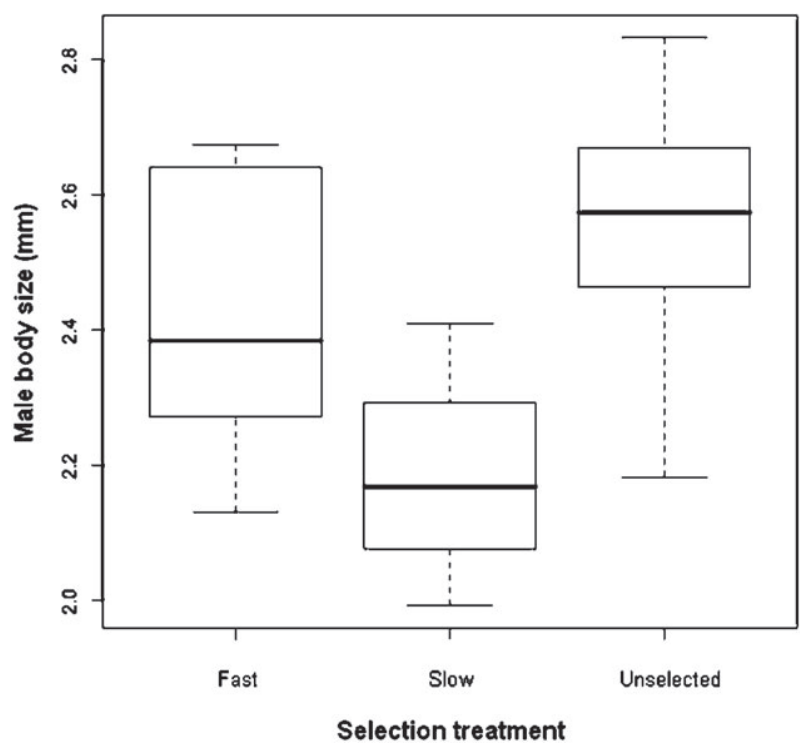

Fig. 3. Male B. anynana selected for slow development time are smaller than unselected stock males, and males selected for fast development (values are medians \pm upper and lower quartiles).

males: median 4 days, range 3-4). Age at first mating was also dependent on the number of fertile sperm ejaculated $(\mathrm{F}=2.712, \mathrm{p}=0.0194, \mathrm{df}=46)$, but unaffected by nonfertile sperm $(p>0.2)$.

\section{DISCUSSION}

We found that B. anynana males selected for fast development ejaculated fewer non-fertile sperm, compared to unselected stock males and males selected for slow development. The fact that males selected for fast development ejaculated fewer non-fertile sperm suggests that, as predicted, there may be a trade-off between development time and ejaculate production in this species. The fact that faster developing males produce fewer non-fertile sperm could be related to allometry. If faster developing males were smaller in size, they might in turn have smaller testes, which could render them constrained in sperm production (Wedell \& Cook, 1998). However, in this study only males from the slow group were significantly smaller, suggesting that this result cannot be explained by a decrease in body size.

In contrast we found no impact of selection history on males' fertile sperm production. The decrease in only non-fertile sperm production observed in the fast developing males may be the result of differences in the timing of fertile and non-fertile sperm production. Fertile and non-fertile sperm follow two distinct developmental pathways (Friedländer, 1997). Fertile sperm production begins during larval development and ceases shortly after pupation, while non-fertile sperm production begins just before or just after pupation, depending on the species. Therefore a reduction in the length of the pupal stage may decrease the time available for non-fertile sperm production, thus reducing the numbers of non-fertile sperm available without affecting fertile sperm production. However, the selection regimes in this study affect larval 
development time whilst having little effect on the duration of the pupal stage (Fischer et al., 2007), so this is unlikely to be the case. Instead, the differences between males may be a by-product of differential resource allocation. If males have finite resources available for both somatic and reproductive demands, and they use proportionally more of these resources in order to develop quickly, by the time they reach pupation they may not have enough resources left to produce large quantities of non-fertile sperm. However, by that stage, fertile sperm production has all but finished. This may also explain why fast developing males produce fewer non-fertile sperm, but we see no effect on fertile sperm. In addition, it has been suggested that stress such as nutrient limitation experienced during larval development can result in males restricting their resource allocation to non-fertile sperm that might be less important to their reproductive success than fertile sperm numbers (Gage \& Cook, 1994). Fast development time in $B$. anynana may translate to lower resource availability and hence these limited resources being preferentially allocated to fertile sperm production. An impact of selection history may only become apparent with repeated copulation as males become increasingly sperm limited. There is a dearth of studies explicitly examining the impact of resource availability on fertile and non-fertile sperm production and the few carried out to date find no such support (e.g. Lewis \& Wedell, 2007).

We found that slow developing males were smaller, produced fewer fertile sperm and took longer to mate. This corroborates in part the results of a previous study, which found that in B. anynana male body size is positively correlated with the numbers of both fertile and nonfertile sperm produced (Lewis \& Wedell, 2007). In the current study, the experimental design did not control for possible pre-copulatory mate choice by females, and potentially these small, slow developing males might have exhibited delayed mating due to female preference for larger males. However, in this species, females show no preference in relation to male body size (Breuker \& Brakefield, 2002). Alternatively, males selected for slow development that produce fewer sperm, might be delaying mating for the first time in an attempt to increase the numbers of sperm available for copulation; in the Lepidoptera, sperm is periodically released from the testes and accumulates in the male sperm storage organ over time (Giebultowicz et al., 1988), and in B. anynana, there is a positive correlation between male age at first mating and both size of the first spermatophore and number of nonfertile sperm transferred (Z. Lewis, unpubl. data). Regardless of the explanation, these results are unexpected, as trade-off theory predicts that selection for slow development should lead to a correlated increase in body size (Roff, 2002), and potentially therefore sperm production. A previous study conducted using the same $B$. anynana lines, similarly reported somewhat ambiguous results; Fischer et al. (2007) found that following selection for long and short development time, males from both groups had smaller pupal masses compared to control males. The effects of selection for slow development observed here could be due to a number of reasons. The responses could in part result from random effects such as inbreeding and genetic drift, or they may be specific to the stock population from which the lines were derived. This is particularly relevant here as all lines originated from the same population, and we had no replication of selection lines. In addition, $B$. anynana is known to have an extremely high genetic load, and males of this species are known to be particularly sensitive to the effects of inbreeding, when compared to females (Saccheri et al., 2005). Alternatively, slower developing males may suffer from an accumulation of deleterious alleles. Deleterious mutants tend to exhibit slow larval development, and thus lines selected for slow larval development may show an increased tendency to accumulate maladaptive traits (Mukai \& Yamazaki, 1971), that may in turn generate aberrant correlations in fitness-related traits such as body size and sperm production.

Here we provide further evidence that males are not limitless in their capacity to reproduce, and may experience trade-offs between reproduction and other aspects of fitness, such as development time. Our results potentially indicate a cost to producing non-fertile sperm, which may have implications for theories on the role of non-fertile sperm in Lepidopteran reproduction.

ACKNOWLEDGEMENTS. The authors wish to thank J. Pijpe for technical advice. They also thank the JSPS, the Leverhulme Trust and the Royal Society for funding, and two anonymous reviewers for helpful comments on the manuscript.

\section{REFERENCES}

Bateman A.J. 1948: Intrasexual selection in Drosophila. Heredity 2: 349-368.

BenRey B. \& DenNo R.F. 1997: The slow-growth-high-mortality hypothesis: a test using the cabbage butterfly. Ecology 78: 987-999.

Bissoondath C.J. \& WikLund C. 1996: Effect of male mating history and body size on ejaculate size and quality in two polyandrous butterflies, Pieris napi and Pieris rapae (Lepidoptera: Pieridae). Funct. Ecol. 10: 457-464.

Brakefield P.M. \& Reitsma N. 1991: Phenotypic plasticity, seasonal climate and the population biology of Bicyclus butterflies (Satyridae) in Malawi. Ecol. Entomol. 16: 291-303.

Brakefield P.M., El Filali E., Van der LaAn R., Breuker C.J., SACCHERI I.J. \& ZWAAN B.J. 2001: Effective population size, reproductive success and sperm precedence in the butterfly, Bicyclus anynana, in captivity. J. Evol. Biol. 14: 148-156.

Breuker C.J. \& Brakefield P.M. 2002: Female choice depends on size but not symmetry of dorsal eyespots in the butterfly Bicyclus anynana. Proc. R. Soc. Lond. (B) 269: 1233-1239.

Chapman T., Miyatake T., Smith H.K. \& Partridge L. 1998: Interactions of mating, egg production and death rates in females of the Mediterranean fruit fly, Ceratitis capitata. Proc. R. Soc. Lond. (B) 265: 1879-1894.

Cook P.A. \& Wedell N. 1996: Ejaculate dynamics in butterflies: A strategy for maximizing fertilization success? Proc. R. Soc. Lond. (B) 263: 1047-1051.

Cook P.A. \& Wedell N. 1999: Non-fertile sperm delay female remating. Nature 397: 486-486.

Drummond B. 1984: Multiple mating and sperm competition in the Lepidoptera. In Smith R.L. (ed.): Sperm Competition and 
the Evolution of Animal Mating Systems. Academic Press, London, pp. 291-370.

Fischer K., ZwaAn B.J. \& BRaKefield P.M. 2007: Realized correlated responses to artificial selection on pre-adult lifehistory traits in a butterfly. Heredity 98: 157-164.

FRIEDLÄNDER M. 1997: Control of the eupyrene-apyrene dimorphism in Lepidoptera. J. Insect Physiol. 43: 1085-1092.

Gage M.J.G. \& CooK P.A. 1994: Sperm size or numbers? Effects of nutritional stress upon eupyrene and apyrene sperm production strategies in the moth Plodia interpunctella (Lepidoptera, Pyralidae). Funct. Ecol. 8: 594-599.

Giebultowicz J.M., Bell R.A. \& Imberski R.B. 1988: Circadian rhythm of sperm movement in the male reproductive tract of the gypsy moth, Lymantria dispar. J. Insect Physiol. 34: $527-532$.

GotTHARD K. 2000: Increased risk of predation as a cost of high growth rate: an experimental test in a butterfly. J. Anim. Ecol. 69: 896-902.

Gotthard K., Nylin S. \& Wiklund C. 1994: Adaptive variation in growth rate - life history costs and consequences in the speckled wood butterfly, Pararge aegeria. Oecologia 99: 281-289.

GuRdon G.B. 1991: Nuclear transplantation in Xenopus. In Kray B. \& Peng B. (eds): Methods in Cell Biology. London Academic Press, London, pp. 299-306.

Jervis M.A., Boggs C.L. \& Ferns P.N. 2005: Egg maturation and its associated trade-offs: a synthesis focusing on Lepidoptera. Ecol. Entomol. 30: 359-375.

Joron M. \& BraKefield P.M. 2003: Captivity masks inbreeding effects on male mating success in butterflies. Nature $\mathbf{4 2 4}$ 191-194.

Kaitala A. \& Wiklund C. 1995: Female mate choice and mating costs in the polyandrous butterfly Pieris rapi (Lepidoptera, Pieridae). J. Insect Behav. 8: 355-363.

LeWIS Z. \& WeDELL N. 2007: Effect of adult diet on male mating behavior in the butterfly, Bicyclus anynana (Lepidoptera, Nymphalidae). J. Insect Behav. 20: 201-213.

MeVEs F. 1902: Über oligopyrene und apyrene spermien und über ihre entstehung, nach beobachtungen an Paludina und Pygaera. Arch. Mikrosk. Anat. 61: 1-84.
Mukai T. \& YamazAKI T. 1971: The genetic structure of natural populations of Drosophila melanogaster. X. Developmental time and viability. Genetics 69: 385-398.

PiJpe J., Fischer K., Brakefield P.M. \& Zwaan B.J. 2006: Consequences of artificial selection on pre-adult development for adult lifespan under benign conditions in the butterfly Bicyclus anynana. Mech. Ageing Dev. 127: 802-807.

RofF D.A. 1992: The Evolution of Life Histories. Chapman and Hall, New York, 552 pp.

RofF D.A. 2002: Life History Evolution. Sinauer Associates, Sunderland, MA, $527 \mathrm{pp}$.

Saccheri I.J., Llyod H.D., Helyar S.J. \& Brakefield P.M. 2005: Inbreeding uncovers fundamental differences in the genetic load affecting male and female fertility in a butterfly. Proc. R. Soc. Lond. (B) 272: 39-46.

Silberglied R.E., Shepherd J.G. \& Dickinson J.L. 1984: Eunuchs: the role of apyrene sperm in Lepidoptera? Am. Nat. 123: 255-265.

Wedell N. 2005: Female receptivity in butterflies. J. Exp. Biol. 208: $3433-3440$.

Wedell N. \& Cook P.A. 1998: Determinants of paternity in a butterfly. Proc. R. Soc. Lond. (B) 265: 625-630.

Wedell N., Gage M.J.G. \& Parker G.A. 2002: Sperm competition, male prudence and sperm-limited females. Trends Ecol. Evol. 17: 313-320.

WikLund C. \& FAgerström T. 1977: Why do males emerge before females? A hypothesis to explain the incidence of protandry in butterflies. Oecologia 31: 153-158.

Zijlstra W.G., ZwaAn B.J. \& Brakefield P.M. 2001: Bad cold for a butterfly? Proc. Sec. Exp. Appl. Entomol. Netherl. Entomol. Soc. 12: 19-23.

Zijlstra W.G., Kesbecke F., Zwan B.J. \& Brakefield P.M. 2002: Protandry in the butterfly Bicyclus anynana. Evol. Ecol. Res. 4: 1229-1240.

Zwaan B.J., Zijlstra W.G., Keller M., Pijpe J. \& Brakefield P.M. 2008: Potential constraints on evolution: sexual dimorphism and the problem of protandry in the butterfly Bicyclus anynana. J. Genet. 87: 395-405.

Received June 11, 2009; revised and accepted October 6, 2009 